\title{
Mean Platelet Volume Measurement
}

National Cancer Institute

\section{Source}

National Cancer Institute. Mean Platelet Volume Measurement. NCI Thesaurus. Code C74730

The determination of the average size of the platelets present in a blood sample. 